\title{
Paraneoplastische Syndrome beim Lungenkarzinom
}

\section{Paraneoplastic Syndromes in Lung Cancer}

Autoren

Institute
H.-P. Hauber

Medizinische Klinik, Forschungszentrum Borstel, Borstel (Ärztlicher Direktor: Prof. Dr. P. Zabel) eingereicht 22.11.2010 akzeptiert nach Revision 7.12.2010

\section{Bibliografie}

DOI http://dx.doi.org/ $10.1055 / \mathrm{s}-0030-1256118$

Online-Publikation: 25.1.2011

Pneumologie 2011; 65:

347-358 @ Georg Thieme

Verlag KG Stuttgart · New York ISSN 0934-8387

\section{Korrespondenzadresse} PD Dr. med. Hans-Peter Hauber Medizinische Klinik

Forschungszentrum Borstel

Parkallee 35

23845 Borstel

hphauber@fz-borstel.de

\section{Zusammenfassung \\ $\nabla$}

Paraneoplastische Syndrome treten bei ca. 10\% aller Patienten mit Lungenkrebs auf. Sie können die Erstmanifestation der Erankung oder ein erstes Zeichen für ein Rezidiv sein. Nach der klinischen Symptomatik können endokrine, hämatologische, neurologische, dermatologische, skelettale, renale, metabolische, kollagenose-vaskulitische und konstitutionelle Syndrome unterschieden werden. In der vorliegenden Übersichtsarbeit werden die Epidemiologie, Pathogenese, klinische Symptomatik und Therapieoptionen der wichtigsten paraneoplastischen Syndrome beim Lungenkarzinom dargestellt.

\section{Einleitung \\ $\nabla$}

Paraneoplastische Syndrome kommen relativ häufig (in ca. $10 \%$ ) beim Lungenkarzinom vor. Sie können die Erstmanifestation eines Lungenkarzinoms darstellen, im Verlauf der Tumorerkrankung auftreten oder auf ein Rezidiv hinweisen $[1,2]$. Die pathophysiologischen Mechanismen, die zur Entstehung von paraneoplastischen Syndromen führen, sind in vielen Fällen nicht gut bekannt. Oftmals entstehen sie durch die Sekretion von Zytokinen oder Hormonen durch den Tumor selbst oder durch die Reaktion des Organismus auf den Tumor mit der Bildung von Antikörpern. Es ist daher nicht verwunderlich, dass keine Korrelation zwischen Tumorgröße und dem Ausmaß der klinischen Symptomatik besteht. Im Folgenden wird die Epidemiologie und allgemeine Pathophysiologie dargestellt sowie eine Übersicht über die paraneoplastischen Syndrome und ihre klinischen Symptome gegeben.

\section{Abstract \\ $\nabla$}

Paraneoplastic syndromes occur in approximately $10 \%$ of all patients with lung cancer. They can be the first manifestation of the disease or of a recurrence. Endocrine, haematological, neuromuscular, dermatological, renal, and metabolic syndromes as well as syndromes involving the connective tissue and constitutional syndromes can be distinguished based on their clinical symptoms. In this review, the epidemiology, pathogenesis, clinical signs and treatment options for the clinically important paraneoplastic syndromes in lung cancer are discussed.

\section{Epidemiologie}

Es wird geschätzt, dass paraneoplastische Syndrome bei ca. 7 bis $15 \%$ aller Krebspatienten auftreten [3]. Wenn die Definition des paraneoplastischen Syndroms um Erkrankungszustände wie Anämie, Hyperkalziämie oder Kachexie erweitert wird, liegt der Prozentsatz der Betroffenen wahrscheinlich noch höher [4]. Es ist also bei jedem fünften Patient mit einem Lungenkarzinom zusätzlich mit einem paraneoplastischen Syndrom zu rechnen.

Das kleinzellige Lungenkarzinom (small cell lung cancer, SCLC) ist am häufigsten mit paraneoplastischen Syndromen assoziiert. Allerdings gibt es auch einige paraneoplastische Syndrome, die häufiger beim nicht-kleinzelligen Lungenkarzinom (Non-small cell lung cancer, NSCLC) auftreten wie beispielsweise die hypertrophe Osteoarthropathie (Marie-Bamberger-Syndrom).

Paraneoplastische Syndrome können der eigentlichen Tumormanifestation vorausgehen und bieten somit in manchen Fällen die Möglichkeit, Malignome in frühen Stadien zu entdecken. Paraneoplastische Syndrome treten in anderen Fällen erst im späten Krankheitsverlauf auf oder sind die ers- 
ten Vorboten für ein Tumorrezidiv. In der Regel haben Lungenkrebspatienten nur ein paraneoplastisches Syndrom. Es gibt jedoch auch Fallberichte von Patienten mit mehreren unterschiedlichen Syndromen [5]. Erweitert man die Definition paraneoplastischer Syndrome wie oben angeführt um Anämie, Kachexie und Hyperkalziämie, ist davon auszugehen, dass mehrere paraneoplastische Syndrome bei einem Patienten in der klinischen Praxis viel öfter anzutreffen sind.

\section{Pathophysiologie}

Die pathophysiologischen Mechanismen, die paraneoplastischen Syndromen zugrunde liegen, sind unterschiedlich und in vielen Fällen ungeklärt. Oft spielen Zytokine oder Hormone bzw. hormon-ähnliche Substanzen eine Rolle, die vom Tumor sezerniert werden wie beispielsweise das ADH (antidiuretisches Hormon) beim SIADH (Syndrom der inadäquaten ADH-Sekretion), das ACTH (adrenocorticotropes Hormon) beim Cushing-Syndrom oder das PTHrP (Parathormon-related Peptide) bei der Hyperkalziämie (s. unten). Daneben kann der Organismus auch selbst auf den Tumor reagieren und Antikörper bilden wie beispielsweise Antikörper gegen spannungsabhängige Kalziumkanäle (voltage gated calcium channel, VGCC) beim Lambert-Eaton-MyasthenieSyndrom.

\section{Einteilung}

Nach der klinischen Symptomatik und den betroffenen Organsystemen lassen sich paraneoplastische Syndrome in endokrine, hämatologische, neurologische, dermatologische, skelettale, renale, metabolische und kollagenose-vaskulitische Syndrome einteilen mit der Kachexie und Fatigue als Sondergruppe konstitutioneller Syndrome [2,4]. Tab. 1 gibt einen Überblick über die unterschiedlichen Syndrome. Da die meisten Raritäten darstellen, werden im Folgenden nur die häufigeren und klinisch relevanteren Syndrome dargestellt.

\section{Endokrine Syndrome}

Lungenkarzinome sezernieren häufig Hormone wie adrenocroticotropes Hormon (ACTH), antidiuretisches Hormon (ADH), Calcitonin, Oxytocin und Parathormon related peptide (PTHrP). Trotz erhöhter Serumkonzentrationen entwickelt nur ein Teil der Patienten klinische Symptome.

\section{Hyperkalziämie}

Eine Hyperkalziämie ist ein häufiger laborchemischer Befund bei Malignompatienten. Die Prävalenz schwankt zwischen 2 und 6\% bei der Erstdiagnose und 8 bis 12\% im Verlauf der Erkrankung [6]. In einer japanischen Studie an 1149 Patienten mit Lungenkarzinom wurde in $6 \%$ der Fälle eine Hyperkalziämie beschrieben [7]. $51 \%$ der Hyperkalziämiepatienten hatten ein Plattenepithelkarzinom, 22\% hatten ein Adenokarzinom und 15\% hatten ein kleinzelliges Lungenkarzinom. In der Mehrzahl lag ein fortgeschrittenes Stadium vor (III oder IV), und die mediane Überlebenszeit war mit 3,8 Monaten sehr kurz [7]. Erhöhte PTHrP-Plasmakonzentrationen finden sich in ca. $80 \%$ aller Patienten mit einer Hyperkalziämie [8].

Tumore können neben PTHrP auch Calcitriol und Zytokine wie beispielsweise den Osteoklasten-aktivierenden Faktor (osteoclast activating factor) sezernieren. Moseley und Mitarbeiter be-
Tab. 1 Paraneoplastische Syndrome beim Lungenkarzinom (nach [2,4,63]).

\begin{tabular}{|c|c|c|}
\hline Gruppe & Häufig & Selten \\
\hline Endokrin & $\begin{array}{l}\text { Hyperkalziämie } \\
\text { SIADH } \\
\text { EAS } \\
\text { Cushing-Syndrom }\end{array}$ & $\begin{array}{l}\text { Akromegalie } \\
\text { Gynäkomastie } \\
\text { Karzinoid-Syndrom } \\
\text { hypokaliämische Alkalose } \\
\text { Hypophosphatämie } \\
\text { Hyperthyreodimus } \\
\text { Hypoglykämie } \\
\text { Hyperkalzitoninämie } \\
\text { erhöhtes LH und FSH }\end{array}$ \\
\hline Hämatologisch & $\begin{array}{l}\text { Anämie* } \\
\text { Polyzythämie }\end{array}$ & $\begin{array}{l}\text { Leukozytose mit Eosinophilie } \\
\text { Leukämoide Reaktion } \\
\text { Thrombozytose/-penie } \\
\text { Amyloidose }\end{array}$ \\
\hline Neurologisch & $\begin{array}{l}\text { periphere } \\
\text { Neuropathie } \\
\text { zerebelläre } \\
\text { Degeneration } \\
\text { LEMS }\end{array}$ & $\begin{array}{l}\text { Mononeuritis multiplex } \\
\text { Enzephalomyelitis } \\
\text { nekrotisierende Myelopathie } \\
\text { tumorassoziierte Retinopathie } \\
\text { Myasthenia gravis } \\
\text { Guillain-Barré-Syndrom } \\
\text { Opsoklonus-Myklonus } \\
\text { subakute Myelopathie } \\
\text { intestinale Pseudoobstruktion }\end{array}$ \\
\hline Dermatologisch & $\begin{array}{l}\text { Akanthosis } \\
\text { nigricans }\end{array}$ & $\begin{array}{l}\text { Erythema gyratum repens } \\
\text { Erythema multiforme } \\
\text { Tylosis } \\
\text { Erythroderma } \\
\text { Sweet-Syndrom } \\
\text { nekrolytisches migrierendes } \\
\text { Erythem } \\
\text { exfoliative Dermatitis } \\
\text { Pruritus und Urtikaria } \\
\text { Hypertrichichosis languinosa }\end{array}$ \\
\hline $\begin{array}{l}\text { Kollagenose- } \\
\text { vaskulitisch }\end{array}$ & Dermatomyositis & $\begin{array}{l}\text { SLE } \\
\text { Polymyositis } \\
\text { Vaskulitis }\end{array}$ \\
\hline Renal & & $\begin{array}{l}\text { Glomerulonephritis } \\
\text { nephrotisches Syndrom }\end{array}$ \\
\hline $\begin{array}{l}\text { Koagulo- } \\
\text { pathisch }\end{array}$ & Thromboembolie & $\begin{array}{l}\text { Thrombophlebitis } \\
\text { DIG } \\
\text { thrombotische Mikroangio- } \\
\text { pathie Trosseau-Syndrom }\end{array}$ \\
\hline Skelettal & $\begin{array}{l}\text { Trommel- } \\
\text { schlegelfinger } \\
\text { HPO }\end{array}$ & \\
\hline Metabolisch & & $\begin{array}{l}\text { Laktatazidose } \\
\text { Hyporurikämie }\end{array}$ \\
\hline Konstitutionell & $\begin{array}{l}\text { Kachexie } \\
\text { Fatigue } \\
\text { Fieber }\end{array}$ & \\
\hline
\end{tabular}

SIADH: Syndrom der inadäquaten ADH-Sekretion. EAS: Ektopes ACTH-Syndrom. Lutenisierendes Hormon. FSH: Follikel-stimulierendes Hormon. LEMS: Lambert-Eaton myasthenisches Syndrom. SLE: Systemisches Lupus erythematodes. DIG: Disseminierte intravasale Gerinnung. HPO: Hypertrophe pulmonale Osteoarthropathie.

* Eine Anämie kann als chronische mikrozytäre, hypochrome Tumoranämie auftreten. Daneben kann auch eine autoimmunhämolytische oder eine mikroangiopathische hämolytische Anämie entstehen.

schrieben die Expression von PTHrP in Lungenkrebszellen [9]. PTHrP weist eine 70\%ige Homologie mit PTH am N-terminalen Ende auf. Beide, PTH und PTHrP, binden an einen gemeinsamen PTH/PTHrP-Rezeptor und haben ähnliche biologische Eigenschaften $[10,11]$. Interessanterweise wird PTHrP auch in normalem Gewebe exprimiert, sodass PTHrP offenbar auch physiologische Funktionen hat [12-14]. Der PTH-Rezeptor ist ein G-Pro- 
tein-gekoppelter Rezeptor [15], der intrazellulär die Bildung von cAMP and Inositoltriphosphat bewirkt $[16,17]$.

PTH stimuliert die Knochenresorption durch Osteoklasten und fördert die Kalziumreabsorption. Gleichzeitg hemmt es die Phosphatreabsorption in den Nierentubuli. Durch PTH-vermittelte Stimulation der renalen $1 \alpha$-Hydroxylase wird vermehrt Calcitriol $\left(1,25-(\mathrm{OH})_{2}-\mathrm{D}_{3}\right)$ gebildet. Calcitriol wiederum fördert die Resorption von Kalzium und Phosphat aus dem Gastrointestinaltrakt. Im Gegensatz zu PTH bewirkt PTHrP keine Steigerung des Kalziumspiegels im Serum. Es fördert auch die Bildung und Progression von Knochenmetastasen. Darüber hinaus reguliert PTHrP das Wachstum von Krebszellen und ist ein wichtiger Faktor für das Überleben dieser Zellen [18-21].

Obwohl PTHrP in der Mehrzahl der Fälle für die Hyperkalziämie verantwortlich ist, ist auch eine ektope Produktion von PTH beim kleinzelligen und beim Plattenepithelkarzinom der Lunge beschrieben worden $[22,23]$. Im Gegensatz zu hämatologischen bösartigen Erkrankungen scheint die extrarenale Bildung von Calcitriol keine bedeutende Rolle in der Entstehung der paraneoplastisch bedingten Hyperkalziämie bei Lungenkarzinomen zu spielen, obwohl SCLC-Zelllinien Calcitriol bilden können [24,25]. Eine Reihe von Zytokinen wie IL-1, IL-6, Transforming Growth Factor (TGF)- $\alpha$, Tumor necrosis factor (TNF)- $\alpha$ und Granulocyte colony stimulating factor (G-CSF) können über eine Stimulation der Osteoklasten die Knochenresorption steigern [14, 26 - 28]. Interessanterweise scheinen auch beim Vorliegen von Knochenmetastasen hormonelle Mechanismen für die Hyperkalziämie verantwortlich zu sein $[29,30]$.

Die typischen klinischen Symptome einer Hyperkalziämie umfassen Anorexie, Nausea, Erbrechen, Polyurie, Polydipsie, Dehydratation und Lethargie. Unbehandelt führt die Hyperkalziämie zum Koma. Ein Nierenversagen und eine Nephrokalzinose können als Spätmanifestationen ebenfalls auftreten. Eine Therapie sollte bei symptomatischen Patienten mit einem Serumkalziumwert $\geq 3 \mathrm{mmol} / \mathrm{l}$ eingeleitet werden. Sie umfasst die Flüssigkeitssubstitution zur Rehydrierung und die forcierte Diurese (mit einem Schleifendiuretikum). Darüber hinaus kommen Biphosphonate zum Einsatz [31].

\section{SIADH (Syndrom der inadäquaten ADH-Sekretion)}

Ein SIADH mit klinischer Symptomatik durch die exzessive Produktion von ADH (antidiuretisches Hormon) kommt bei ca. 10\% aller Patienten vor [32]. Erhöhte Serumspiegel von ADH können bei 30 bis $70 \%$ aller Patienten mit einem Lungenkarzinom nachgewiesen werden [33]. Allerdings führen erhöhte ADH-Konzentrationen nicht immer zu einer klinischen Symptomatik [34-36]. Die Symptomatik des SIADH reicht von Anorexie, Übelkeit und Erbrechen bis zu Verwirrungszuständen, Krämpfen, Somnolenz und Koma. Ein schneller Abfall der Natriumkonzentration im Serum kann ein Hirnödem verursachen. Klinische Symptome treten bei Natriumserumkonzentrationen unter $125 \mathrm{mmol} / \mathrm{l}$ auf. List und Mitarbeiter fanden in einer retrospektiven Analyse von Patienten mit SIADH eine mittlere Natriumkonzentration im Serum von $117 \mathrm{mmol} / \mathrm{l}$ [32].

Die Hyponatriämie im Rahmen eines SIADH ist offenbar ein wichtiger prognostischer Faktor beim kleinzelligen Lungenkarzinom. Hansen und Kollegen untersuchten retrospektiv $453 \mathrm{~Pa}-$ tienten mit einem kleinzelligen Lungenkarzinom [37]. Patienten mit erniedrigten Natriumserumkonzentrationen hatten signifikant kürzere mediane Überlebenszeiten als die Patienten mit normalen Werten (7,1 Monate vs. 11,2 Monate).
Das SIADH wird biochemisch über die verminderte Natriumkonzentration im Serum mit verminderter Plasmaosmolalität in Kombination mit einer erhöhten, inappropriaten Urinosmolalität und persistierender Natriumausscheidung definiert. Neben ADH sind auch andere Hormone wie beispielsweise ANP (atriales natriuretisches Hormon) als mögliche Mediatoren in Pathogenese des SIADH diskutiert worden. Allerdings wurden konsistent nur erhöhte ADH-Konzentrationen bei Malignompatienten nachgewiesen [38].

ADH wird physiologischerweise von dem Hypophysenhinterlappen (Neurohypophyse) sezerniert. Beim paraneoplastischen SIADH können auch Tumorzellen ADH freisetzen [36]. Ein anderer möglicher Mechanismus ist die inappropriate Stimulation der Freisetzung von $\mathrm{ADH}$ aus dem Hypothalamus durch periphere Barorezeptoren [38]. ADH (auch als Vasopressin bezeichnet) bindet an Vasopressin (V)2-Rezeptoren, die an der basolateralen Seite der Epithelzellen in den Sammelrohren der Niere lokalisiert sind. Als Folge wird die Genexpression von Aquaporin-2 und der Einbau von präformierten Aquaporin-Wasserkanälen in die apikale Zellmembran gesteigert. Durch die Aquaporin-Kanäle wird vermehrt Wasser resorbiert [39]. Die Identifizierung der V2-Rezeptoren hat zur Entwicklung von Antagonisten, den Vaptanen, geführt, die therapeutisch beim SIADH eingesetzt werden können (s. unten).

Ein interessanter Aspekt beim SIADH ist die Entwicklung eines partiellen „ADH-Escape“-Phänomen. Dies schützt den Organismus vor einer fortlaufenden Flüssigkeitsretention [40]. Typischerweise beträgt die zusätzliche Flüssigkeitsmenge beim SIADH auch nur 2-31 und es finden sich auch keine Ödeme oder Anasarka.

Obwohl die Konzentration oder der Effekt von ADH beim SIADH inadäquat sind, weisen bis zu einem Drittel der Patienten im Verlauf eine Sollwertverstellung ihrer Osmolalität nach unten auf [41]. Diese Patienten haben typischerweise stabile Natriumwerte im Plasma zwischen $125 \mathrm{mmol} / \mathrm{l}$ und $135 \mathrm{mmol} / \mathrm{l}$. Es ist wichtig, diese Patienten mit einem neuen, stabilen Sollwert für die Natriumkonzentration zu identifizieren. Die Korrektur dieser Hyponatriämie ist unnötig und höchstwahrscheinlich ineffektiv, da eine Erhöhung der Plasmaosmolalität bei diesen Patienten nur zu vermehrter ADH-Sekretion und Durst führen wird.

In der oben zitierten Studie von List und Mitarbeitern führte eine Chemotherapie in $80 \%$ der Fälle in kurzer Zeit (weniger als drei Wochen) zu einer Resolution des SIADH [32]. Adjuvante Therapiemaßnahmen umfassen die Flüssigkeitsrestriktion auf 800 $1000 \mathrm{ml}$ pro Tag in milden Fällen. In schweren Fällen wird die Infusion hypertoner Kochsalzlösung empfohlen (z.B.: 200-300 ml $5 \% \mathrm{NaCl}$ in 3-4 h). Mit den Vaptanen als V2-Rezeptor-Antagonisten steht eine weitere, wirksame Behandlungsoption zur Verfügung. In Deutschland ist Tolvaptan zur Behandlung des SIADH zugelassen. Die Wirkung von Tolvaptan bei einer Hyponaträmie wurde im SALT-1 und SALT-2 gezeigt [42]. In diesen Multicenter-Studien wurde der Effekt von Tolvaptan $(\mathrm{n}=225)$ mit Plazebo $(\mathrm{n}=223)$ an Patienten mit einer Hyponaträmie verglichen. Tolvaptan führte zu einer signifikanten Zunahme der Natriumkonzentration im Plasma mit Durst, Mundtrockenheit und gesteigerter Diurese als häufigsten Nebenwirkungen.

\section{Ektopes ACTH-Syndrom und Cushing-Syndrom}

In bis zu 50\% aller Lungenkrebspatienten (fast immer kleinzelliges Karzinom) finden sich erhöhte ACTH-Serumspiegel $[43,44]$. Ein manifestes Cushing-Syndrom ist jedoch sehr viel seltener [45]. Es wird auch selten in voller klinischer Ausprägung beob- 
achtet. Am häufigsten kommt es zu peripheren Ödemen, proximaler Mypopathie, Vollmondgesicht, Gewichtsverlust, hypokaliämischer Alkalose und Hyperglykämie [46].

Grundsätzlich kann das ektope ACTH-Syndrom (EAS) in zwei Typen eingeteilt werden: eins mit nachgewiesener, klinisch manifester Tumorerkrankung und eins mit einem okkulten Neoplasma [47]. Das Cushing-Syndrom beim kleinzelligen Lungenkarzinom ist ein typischer Vertreter der ersten Gruppe, wohingegen das Bronchuskarzinoid ein klassischer Vertreter eines okkulten Tumors ist, der ein EAS auslöst.

Kleinzellige Lungenkarzinome mit EAS sind gegenüber Chemotherapie resistenter. Zusätzlich führt der Hyperkortisolismus in vielen Fällen zu lebensbedrohlichen Komplikationen im Rahmen der Chemotherapie, die die Prognose verschlechtern [47]. In einer retrospektiven Studie an 545 Patienten mit einem kleinzelligen Lungenkarzinom fanden Shepherd und Mitarbeiter $23 \mathrm{~Pa}-$ tienten (4,5\%) mit einem Cushing-Syndrom und ektoper ACTHProduktion [46]. In dieser Patientengruppe lag die Ansprechrate der Chemotherapie nur bei $46 \%$ und das mediane Überleben bei 3,57 Monaten.

Einige Patienten mit einem Cushing-Syndrom haben normale ACTH-Konzentrationen im Serum [48]. In dieser Patientengruppe finden sich teilweise erhöhte Konzentrationen von ACTH-Vorläufermolekülen wie dem Proopiomelanocortin (POMC). Physiologischerweise wird ACTH in den Zellen des Hypophysenvorderlappens aus POMC gebildet („Cleavage“). Die Prozessierung von ACTH ist in anderen Zellen wahrscheinlich wesentlich ineffektiver. POMC-exprimierende Zellen können ACTH-Vorstufen und ACTH-ähnliche Peptide sezernieren. ACTH-Vorstufen können im Serum von Patienten mit EAS detektiert werden [49]. Neben SCLC-Zellen exprimieren auch Bronchuskarzinoidzellen POMC [50-52].

Die Therapie des EAS bzw. des paraneoplastischen Cushing-Syndroms besteht in der Behandlung des zugrunde liegenden Tumors. In der Mehrzahl der Fälle ist durch die Therapie des Malignoms eine Rückbildung der paraneoplastischen Symptome zu erwarten. Besteht die Möglichkeit, sollte eine Resektion des Primärtumors erwogen werden, da diese die Symptomatik komplett beseitigt.

\section{Hämatologische Syndrome}

Bei Lungenkrebspatienten finden sich oft hämatologische Auffälligkeiten in Form von Anämie, Leukozytose, Thrombozytose und/ oder Eosinophilie. Insbesondere eine Anämie ist ein sehr häufiger Befund bei einer Krebserkrankung. In einer Untersuchung lag die Rate der unbehandelten Lungenkrebspatienten mit einer Hämoglobinkonzentration unter bzw. bis $12 \mathrm{~g} / \mathrm{dl}$ bei 38\%. 80\% der Patienten, die eine Chemotherapie erhielten, waren zu einem Zeitpunkt anämisch [53]. Im Durchschnitt weisen mehr als ein Drittel aller Patienten nach drei Zyklen einer Chemotherapie eine Anämie auf [54]. Mehrere Faktoren spielen bei der Entstehung einer Anämie bei Tumorerkrankungen eine Rolle. Neben Blutungen, Hämolyse, Infiltration des Knochenmarks durch maligne Zellen und Malnutrition können Zytokine wie TNF- $\alpha$, IL-1, IL-6 und Interferon (IFN)- $\gamma$ die Erythropoese inhibieren und damit über die verminderte Bildung von Erythrozyten eine Anämie verursachen. Natürlich ist die myelotoxische Nebenwirkung einer Chemotherapie einer der häufigsten Gründe für eine Anämie bei Tumorpatienten [55]. Eine Anämie im Rahmen einer Krebserkrankung sollte mit dem Ziel einer Verbesserung der Lebensqualität behandelt werden. Neben der Transfusion stehen Erythropoese-stimulierende Substanzen zur Verfügung, deren Nutzen aber nicht ganz sicher ist. In einer Cochrane-Metaanalyse an 13933 Patienten in 53 Studien fand sich eine Steigerung der Mortalität und verkürzte Überlebenszeit in der Gruppe der Patienten, die Epoetin oder Darbepoetin erhielten [56]. Eine neuere Metaanalyse konnte dagegen keine signifikante Verschlechterung der Prognose durch die Gabe dieser Substanzen nachweisen [57]. Die aktuelle S3-Leitlinie der Deutschen Gesellschaft für Pneumologie und Beatmungsmedizin zum Lungenkarzinom gibt Erythropoetin als mögliche Therapie zur Vermeidung von Transfusionen bei anämischen Patienten mit Lungenkarzinom unter Chemotherapie an, wobei der Zielwert für Hämoglobin bei maximal $12 \mathrm{~g} / \mathrm{dl}$ liegen sollte [58]. Auf ein mögliches erhöhtes Risiko thrombembolischer Komplikationen sollte hingewiesen werden, ebenso auf einen möglichen negativen Einfluss auf das Überleben. Vom Einsatz von Erythropoetin zur Behandlung der Tumoranämie bei Patienten mit nicht-kleinzelligem Lungenkarzinom, die keine zytostatische Therapie erhalten, wird außerhalb von Studien abgeraten [58].

Das Lungenkarzinom kann über die Bildung von G-CSF (granulocyte-colony stimulating factor) die Leukozytopoese steigern und somit eine Leukozytose verursachen [59]. Weiterhin konnte auch eine Assoziation der Bildung von GM-CSF (granulocyte macrophage-CSF) und IL-6 durch Lungenkarzinome mit dem Auftreten einer Leukozytose nachgewiesen werden [60,61].

\section{Koagulopathien}

Beim Lungenkarzinom findet sich eine Reihe unterschiedlicher Koagulopathien. Hierzu gehören das Trousseau-Syndrom (wandernde oberflächliche Thrombophlebitis), Thrombose der tiefen Venen und Thrombophlebitis, die disseminierte intravasale Gerinnung (DIG), die thrombotische Mikroangiopathie und die nicht-thrombotische Mikroangiopathie. Die Inzidenz von venösen Thromboembolien (VTE) liegt für Krebspatienten bei 40 100 Fällen pro 1000 Personenjahren, verglichen mit 1 -2 Fällen pro 1000 Personenjahren in der allgemeinen Bevölkerung [62]. In einer Studie von Chew und Kollegen an 91933 Patienten mit einem neu diagnostizierten Lungenkarzinom erlitten 3\% innerhalb von zwei Jahren eine VTE [63]. Das Auftreten einer VTE war dabei mit einem höheren Mortalitätsrisiko innerhalb der nächsten zwei Jahre assoziiert. Dies galt sowohl für kleinzellige als auch nicht-kleinzellige Karzinome. Lungenkrebs ist einer der größten Auslöser von VTE [64].

Pathophysiologisch spielen bei der Gerinnungsaktivierung durch Tumorzellen zwei Faktoren eine wichtige Rolle: Gewebefaktor (Tissue factor, TF) und prokoagulatorischer Faktor vom Malignom (cancer procoagulant, CP) [65]. Humanes TF ist ein physiologischer Aktivator der Blutgerinnung. Im nicht-kleinzelligen Lungenkarzinom findet sich eine gesteigerte Expression von TF und alternativen Splicevarianten [66]. Offenbar korreliert die Expression von TF mit der Prognose. Biologisch aktive Mikropartikel, die TF enthalten, sind im Blutkreislauf von Krebspatienten nachgewiesen worden. Diese Partikel stammen möglicherweise aus dem Tumor. Durch die Mikropartikel-vermittelte TF-Aktivität ergibt sich eine Verbindung zwischen Krebserkrankung und Thrombose. Hier scheint ein wichtiger Faktor in der Pathogenese des prothrombotischen Zustands bei Krebspatienten zu liegen [62].

Grundsätzlich sollten thrombembolische Ereignisse bei Krebspatienten in gleicher Weise wie bei anderen Ätiologien behandelt werden. Ein Problem bei der Antikoagulation können ein zentral wachsender Tumor mit Blutungsneigung oder Hirnmetastasen darstellen. Die Daten aus der Literatur weisen auf eine Über- 
legenheit von niedermolekularem Heparin (low molecular weight heparin, LMWH) über unfraktioniertes Heparin bei der initialen Therapie einer VTE hin [67]. In der Langzeittherapie reduzieren LMWH die Rate an VTE, beeinflussen aber nicht die Mortalität im Vergleich zur Therapie mit oralen Antikoagulanzien [67]. Bei Krebspatienten mit vorherigen thrombolischen Ereignissen verlängert Heparin das Überleben. Dies gilt insbesondere für Patienten mit einem kleinzelligen Lungenkarzinom im Stadium Limited Disease [68]. Dagegen scheint eine orale Antikoagulation das Leben nicht zu verlängern. Nur für Patienten mit einem kleinzelligen Lungenkarzinom im Stadium Extensive Disease ergibt sich durch eine orale Antikoagulation offenbar ein Überlebensvorteil von sechs Monaten [68].

Im Zusammenhang mit thrombembolischen Ereignissen beim Lungenkarzinom sind auch Therapie-induzierte VTE zu berücksichtigen. Dies gilt insbesondere für die neuen Substanzen wie beispielsweise den Anti-VEGF (vascular endothelial growth factor)-Antikörper Bevacizumab. Eine Metaanalyse von Nalluri und Kollegen wertete die Verläufe von 7956 Patienten mit soliden Tumoren aus 15 klinischen Studien aus [69]. Patienten, die mit Bevacizumab behandelt wurden, hatten gering, aber signifikant erhöhtes Risiko fur eine VTE (Relatives Risiko: 1,31).

In einer anderen Studie wurden die Daten von 1978 Patienten aus drei klinischen Studien ausgewertet [70]. Patienten, die eine Chemotherapie erhielten, erlitten öfter eine VTE als Patienten, die keine Therapie erhielten. Dies war unabhängig vom Stadium der Erkrankung. Für eine Therapie mit Erlotinib war kein Unterschied zwischen Behandelten und Unbehandelten zu erheben.

\section{Skelettale Syndrome}

Trommelschlegelfinger und hypertrophe pulmonale Osteoarthropathie (HPO, Marie-Bamberger-Syndrom) gehören zu den häufigsten paraneoplastischen skelettalen Syndromen ( $\bullet$ Abb. 1). Sie finden sich am häufigsten beim Plattenepithel- sowie beim Adenokarzinom [6]. Trommelschlegelfinger treten in allen Tumorstadien auf und sind häufiger als eine HPO. Sridhar und Kollegen beschrieben Trommelschlegelfinger in 32 von 111 Patienten mit histologisch gesichertem Lungenkarzinom (29\%) [71]. Frauen waren häufiger als Männer betroffen [71]. Bei Erwachsenen sind Trommelschlegelfinger in mehr als $80 \%$ der Fälle Ausdruck einer malignen Grunderkrankung [6]. Die Angaben zur Häufigkeit der HPO schwanken. Stenseth und Kollegen untersuchten retrospektiv 1888 Patienten mit einem primären oder sekundären Tumor der Lunge [72]. Die Rate der HPO lag in der Studie bei 10\% (Adenokarzinom: 11,8\%; Plattenepithelkarzinom: 9,4\%; großzelliges Karzinom: 14,2\%; kleinzelliges Karzinom: 5\%). In einer anderen Studie lag die Rate der HPO infolge eines kleinzelligen Lungenkarzinoms unter $1 \%$ [73].

Trommelschlegelfinger sind klinisch durch eine Schwellung der terminalen Phalangen der Hände oder Füße gekennzeichnet. Die HPO manifestiert sich als systemische Erkrankung mit schmerzhafter symmetrischer Arthropathie, die typischerweise die Sprung- und Hüftgelenke betrifft, und periostaler Knochenneubildung an den distalen Extremitäten (Tibia, Fibula, Radius, Ulna). Die Patienten beschreiben einen tief sitzenden Schmerz als Folge der Periostitis. Die Gelenke sind schmerzhaft und hyperämisch [2].

Die genaue Pathogenese für die Entstehung von Trommelschlegelfingern und der HPO ist unbekannt. Bei Trommelschlegelfingern findet sich eine Proliferation von Bindegewebe in unmittelbarer Nähe der Nagelmatrix. Bei der HPO können Hyperplasie der Gefäße, Ödembildung sowie exzessive Proliferation von Fibro-

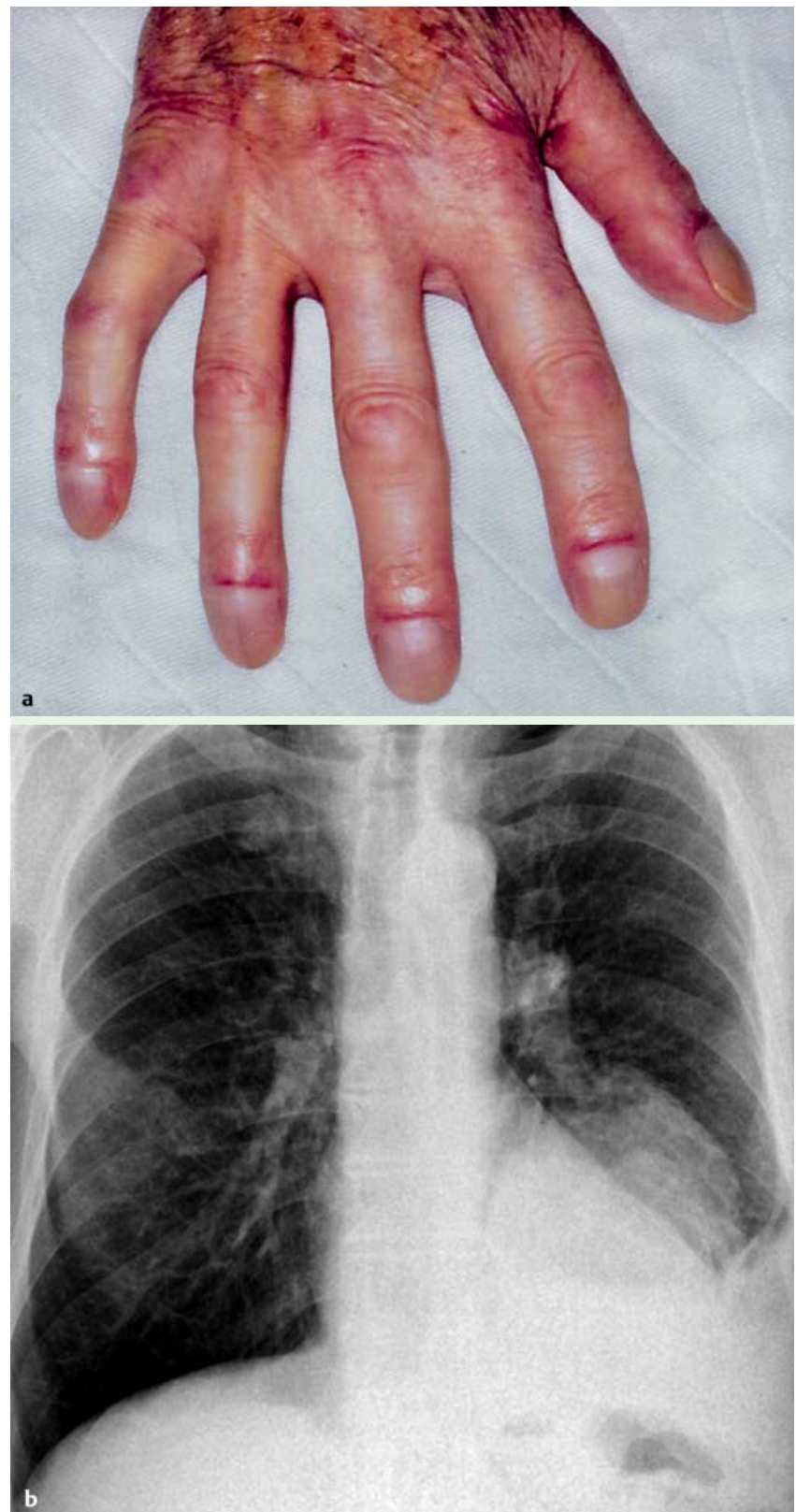

Abb. 1 Trommelschlegelfinger (a) bei einem Patienten mit einem Plattenepithelkarzinom im linken Lungenunterlappen (b).

blasten und Osteoblasten histochemisch nachgewiesen werden [74]. Neurogene, hormonelle und vaskuläre Mechanismen sind in der Vergangenheit diskutiert worden [75]. Neuere Untersuchungen weisen auf eine wichtige Rolle von PDGF und insbesondere VEGF in der Pathogenese von Trommelschlegelfingern und HPO hin [76]. Olan und Kollegen berichteten von dem Fall einer jungen Lungenkrebspatientin mit HPO. Die Serumkonzentration von VEGF war bei der Patientin erhöht. Nach der chirurgischen Entfernung des Tumors fielen die VEGF-Werte und die HPO verschwand. Die histochemische Untersuchung des Resektats zeigte die Expression von VEGF-mRNA, was auf eine ektope Produktion von VEGF hinwies [77]. In einer anderen Studie untersuchten Silveira und Kollegen 24 Patienten mit HPO [78]. 7 Patienten dieser Gruppe hatten ein Lungenkarzinom. Die VEGF-Serumkonzentrationen der Patienten mit einem Lungenkarzinom und HPO lagen signifikant höher als in einer Vergleichsgruppe von Lungenkrebspatienten ohne HPO. Interessanterweise wurden kürzlich zwei 
Fälle von Patienten mit kolorektalen Karzinomen beschrieben, die unter einer Langzeittherapie mit dem Anti-VEGF-Antikörper Bevacizumab Trommelschlegelfinger und HPO entwickelten [79]. Diese Beobachtung wirft neue Fragen zur Rolle von VEGF in der Pathogenese der Trommelschlegelfinger und der HPO auf. Auch Prostaglandine (PG) und insbesondere PG E2 scheinen in die Pathogenese der HPO involviert zu sein. Uppal und Mitarbeiter konnten bei primärer HPO Mutationen in der 15-Hydroxyprostaglandin-Dehydrogenase und erhöhte PG-E2-Konzentrationen nachweisen [80]. Inwieweit dies für die paraneoplastische HPO gilt und ob durch eine Hemmung von PG E2 eine therapeutische Beeinflussung möglich ist, bleibt abzuwarten.

Die Symptome einer HPO können nach einer Resektion des Tumors verschwinden. Bei inoperablen Patienten besteht die übliche Therapie in der Gabe von nicht-steroidalen Antiphlogistika oder Biphosphonaten [81].

\section{Kollagenose- und Vaskulitis-Syndrome}

Bei den Kollagenosen sind die Dermatomyositis und die Polymyositis am häufigsten mit einem Malignom assoziiert: in $40 \%$ aller Fälle. Neben dem Ovarialkarzinom ist das kleinzellige Lungenkarzinom das häufigste Malignom [82]. In einer retrospektiven Untersuchung an 24 Patienten mit Dermatomyositis/Polymyositis und Lungenkrebs trat die paraneoplastische Symptomatik im Allgemeinen vor der Entdeckung des Malignoms auf und ein kleinzelliges Karzinom war der häufigste histologische Typ [83]. Auf der anderen Seite könnten auch Kollagenosen selbst einen Risikofaktor für die Entstehung eines Malignoms darstellen. In einer retrospektiven Studie an 153 Patienten mit einer Kollagenose und einem Lungenkarzinom konnte eine Beziehung zwischen Rauchen und Krebsentstehung bei Patienten mit rheumatoider Arthritis und Dermatomyositis/Polymyositis gezeigt werden [84]. Patienten mit einer Lungenfibrose im Rahmen einer systemischen Sklerose erkrankten am häufigsten an einem bronchioloalveolären Karzinom oder einem Adenokarzinom. Letztendlich ist die Zuordnung von Ursache und Folge zwischen Kollagenose und Tumorerkrankung in vielen Fällen nicht eindeutig zu treffen.

Bei der Dermatomyositis finden sich Infarkte, eine perifaszikuläre Atrophie, Schwellung und Nekrose der Endothelzellen, Ablagerung von Immunkomplexen und Heraufregulierung des Myozyten-spezifischen MHC I im Muskel. Histopathologisch weist die Haut Hyperkeratose, Degeneration und Apoptose epidermaler Basalzellen, eine gesteigerte Muzinexpression und eine zellarme Dermatitis auf. Der genaue pathogenetische Zusammenhang zwischen Malignom und Myositis ist nicht vollständig verstanden [85]. Die Dermatomyositis wurde lange Zeit als humoral vermittelte Erkrankung angesehen. Neuere Untersuchungen weisen jedoch darauf hin, dass zellvermittelte Mechanismen und eine Dysregulation der Mechanismen der angeborenen Immunität eine wichtigere Rolle spielen [86]. So werden beispielsweise Myositis-spezifische Autoantigene in hohen Konzentrationen in regenerierenden Zellen myositischer Muskeln und in Krebszellen exprimiert [87].

Klinisch äußert sich die Polymyositis mit Muskelschwäche und Muskelschmerzen. Typischerweise ist die proximale Muskulatur betroffen. Die Dermatomyositis weist charakteristische Hautsymptome wie lilafarbene ödematöse Erytheme (v.a. periorbital), Gottron-Papeln und Teleangiektasien an den Fingernägeln auf. Die Therapie der Wahl besteht bei der Dermatomyositis in der Gabe von Glukokortikosteroiden [88].

\section{Neurologische Syndrome}

Paraneoplastische neurologische Syndrome sind selten bei Krebserkrankungen, jedoch häufig die Ursache für große Einschränkungen und Behinderungen im täglichen Leben. Sie beeinflussen damit ganz wesentlich die Lebensqualität von Tumorpatienten [89]. Beim Lungenkarzinom treten paraneoplastische neurologische Syndrome fast ausschließlich beim kleinzelligen Karzinom auf. Die Prävalenz wird mit 4 bis 5\% angegeben, liegt aber möglicherweise niedriger [90-92].

Ein wichtiger Aspekt in der Pathogenese paraneoplastischer neurologischer Syndrome ist in der Antigengemeinschaft des zentralen Nervensystems (ZNS) und Tumoren (insbesondere des kleinzelligen Lungenkarzinoms) zu sehen. Die Immunantwort des Organismus auf das Malignom kann somit kreuzreaktiv auch Strukturen des Nervensystems schädigen und somit paraneoplastische Symptome hervorrufen. Es sind eine Reihe von Antikörpern im Serum und im Liquor bei paraneoplastischen neurologischen Syndromen beschrieben worden.

Es gibt eine Vielzahl unterschiedlicher paraneoplastischer neurologischer Syndrome beim Lungenkarzinom. Die Diagnose wird in der Regel nach Ausschluss anderer Ursachen wie Elektrolytstörungen, Metastasen, Ischämien, Blutungen, Infektionen oder medikamentös-toxischen Effekten gestellt. Zu den häufigeren paraneoplastischen neurologischen Syndromen zählen das LambertEaton-myasthenische-Syndrom (LEMS), limbische Enzephalopathie, Polyneuropathie (PNP), zerebelläre Degeneration, Retinopathie, Opsoklonus-Myoklonus und autonome Neuropathie $[90,93]$.

Bei fast allen paraneoplastischen neurologischen Syndromen sind antineuronale Antikörper Typ I nachweisbar, die gegen den Zellkern gerichtet sind, die sog. Anti-Hu-Antikörper [94]. Das HuAntigen findet sich in Nervenzellen, die bei Gesunden durch die Blut-Hirn-Schranke vom Immunsystem getrennt sind. Daher haben gesunde Personen keine Anti-Hu-Antikörper. Der Anti-HuAntikörper erkennt eine Familie RNA-bindender Proteine (HuD, HuC, Hel-N1 und Hel-N2), die in den Zellkernen von Neuronen und SCLC-Zellen exprimiert werden [95,96]. Bei ca. 20\% aller Patienten mit einem kleinzelligen Lungenkarzinom werden im Serum Anti-Hu-Antikörper nachgewiesen. Allerdings entwickeln nicht alle dieser Patienten neurologische Paraneoplasien [93,97]. Obwohl die Hu-Antigene eine entscheidende Rolle in der Entstehung und Persistenz des neuronalen Phänotyps spielen, ist ihre Rolle in Tumorzellen ungeklärt. Es gibt sogar keine Evidenz dafür, dass die Anti-Hu-Antikörper ursächlich für die neuronale Schädigung verantwortlich sind $[98,99]$. Die Antikörper sind möglicherweise nur ein Teil einer komplexeren Immunantwort, die ursprünglich gegen das Tumorwachstum gerichtet war und sich im Verlauf auch (fälschlicherweise) gegen andere (neuronale) Strukturen richtete [100]. Unabhängig von seiner exakten pathophysiologischen Rolle ist der Anti-Hu-Antikörper ein wertvoller diagnostischer Marker [101]. Ein weiterer wichtiger Hinweis für eine wichtige Rolle einer autoimmun vermittelten Entzündung in der Pathogenese paraneoplastischer neurologischer Syndrome ist die lymphozytäre Infiltration in Arealen des ZNS, die mit der klinischen Symptomatik korrespondieren, im Rahmen einer Autopsie. Lymphozyteninfiltrate finden sich auch in unmittelbarer Nachbarschaft des Tumors, was die Hypothese stützt, dass eine körpereigene Immunantwort das Tumorwachstum hemmt [102]. Graus und Kollegen untersuchten 200 Patienten mit einer paraneoplastischen Enzephalomyelitis (PEM) und Nachweis von Anti-Hu-Antikörpern. In 83\% der Fälle konnte histologisch oder radiologisch ein Tumor nachgewiesen werden, der in $74 \%$ einem 
kleinzelligen Lungenkarzinom entsprach [103]. Die PEM ging der Tumordiagnose in $71 \%$ voraus und war in $87 \%$ der Fälle ein Zeichen für eine Progression oder ein Tumorrezidiv. Die Prognose von Malignompatienten mit einer PEM ist eingeschränkt $[103,104]$.

Die subakute periphere Neuropathie ist die häufigste neurologische Paraneoplasie beim kleinzelligen Lungenkarzinom [2]. Es kommen sowohl sensorische als auch motorische Ausfälle vor, die über Wochen oder Monate progredient verlaufen. Der Nachweis von Anti-Hu-Antikörpern im Serum kann bei der Diagnosestellung helfen.

Opsoklonus-Myoklonus ist eine weitere seltene neurologische Neoplasie, die am häufigsten mit einem kleinzelligen Lungenkarzinom assoziiert ist $[105,106]$. Als Opsoklonus werden irreguläre, kontinuierliche und konjugierte chaotische Sakkaden der Augen bezeichnet. Wenn der Opsoklonus mit anderen Symptomen auftritt, die auf eine Beteiligung des ZNS hinweisen (Kopf, Myoklonus der abhängigen Partien, Rumpfataxie) wird das Syndrom als Opsoklonus-Myoklonus bezeichnet. Der Nachweis anti-neuronaler Antikörper im Serum der Patienten weist auf eine schlechte Prognose hin [107]. Hassen und Kollegen untersuchten Patienten mit einem kleinzelligen Lungenkarzinom und einem Opsoklonus-Myoklonus [108]. Die Patienten, die keine Chemotherapie erhielten, starben innerhalb von drei Monaten. Dagegen berichtete die Hälfte der Patienten, die mit Zytostatika behandelt wurden, von einer Verbesserung der neurologischen Symptomatik. Einige dieser Patienten hatten sogar sehr lange Überlebenszeiten ( 6 bis zu 84 Monate).

Das LEMS ist wahrscheinlich das bekannteste paraneoplastische neurologische Syndrom. Es tritt bei ca. 3\% aller Patienten mit einem kleinzelligen Lungenkarzinom auf [91]. Beim LEMS werden regelhaft Antikörper gegen präsynaptische spannungsaktivierte Kalziumkanäle nachgewiesen. Diese Antikörper vermindern den Kalziumeinstrom in die präsynaptischen Endigungen und verhindern so die Bindung von intrazellulären Vesikeln an die präsynaptische Membran und die Freisetzung von Acetylcholin. Die Antikörper sind am häufigsten gegen spannungsabhängige (voltage-gated) P/Q-Kalziumkanäle (calcium channels, VGCC) gerichtet, aber es finden sich auch Antikörper, die gegen spannungsabhängige N-Kalziumkanäle gerichtet sind [109]. Neben dem LEMS findet sich auch ein niedriger Titer von Antikörpern gegen P/Qund N-Kalziumkanäle in ungefähr der Hälfte von Patienten mit paraneoplastischen enzephalomyeloneuropathischen Komplikationen [109].

Klinisch ist das LEMS durch eine progrediente Muskelschwäche der proximalen Muskeln der unteren Extremitäten charakterisiert. Die Symptomatik kann morgens stärker ausgeprägt sein und sich im Verlauf des Tages bessern. Fatigue, Mundtrockenheit und Ptosis sind ebenfalls typisch [110]. Im Gegensatz zur Myasthenia gravis beobachtet man beim LEMS eine Fazilitation ( $\mathrm{Zu}$ nahme der Kraft nach Anstrengung).

Interessanterweise scheinen Patienten mit einem kleinzelligen Lungenkarzinom und einem LEMS eine bessere Prognose zu haben [111]. Dies muss jedoch sicherlich in prospektiven Studien weiter abgeklärt werden.

Bei der PEM finden sich entzündliche Infiltrate und ein Verlust von Neuronen in verschiedenen Gebieten des Nervensystems [112]. Dies führt in der Regel zu schweren neurologischen Ausfällen. In mehr als 70\% der Fälle geht die PEM der Diagnose eines kleinzelligen Lungenkarzinoms voraus [103]. Bei der Mehrzahl der Patienten mit einer PEM lässt sich der anti-neuronale Antikörper Anti-Hu nachweisen [113,114].
Zur Behandlung paraneoplastischer neurologischer Syndrome sind zwei unterschiedliche generelle Therapieansätze versucht worden. Grundlage für diese therapeutischen Ansätze ist die Hypothese, dass die neurologische Symptomatik durch immunologische Mechanismen verursacht wird. Hieraus ergibt sich, dass diese Syndrome entweder durch die Eliminierung der Antigenquelle (also des Tumors) oder Unterdrückung der Immunantwort (Immunsuppression) behandelt werden können. Der Erfolg einer Chemotherapie bei paraneoplastischen neurologischen Syndromen und kleinzelligem Lungenkarzinom ist variabel $[115,116]$. In manchen Fällen führt die zytostatische Behandlung zu einer anhaltenden Symptomverbesserung [2]. Das LEMS kann mit 3,4Diaminopyridin oder intravenöser Immunglobulingabe behandelt werden. Dieser Ansatz verbessert offenbar die Muskelkraft, wenngleich die Evidenz für solche Therapieansätze aus Studien begrenzt ist [117]. In einer neueren Metaanalyse bestätigte sich die Wirksamkeit von 3,4-Diaminopyridin beim LEMS in verschiedenen Studien, sodass es als Medikament der Wahl in der Behandlung des LEMS anzusehen ist [118]. Bei anderen paraneoplastischen neurologischen Syndromen scheint die Kombination aus einer raschen Chemotherapie und Immuntherapie bzw. Immunsuppression wirksam zu sein [119-121].

\section{Dermatologische Symptome}

Dermatologische Symptome sind in der Regel unspezifisch und erlauben keine Unterscheidung zwischen einer malignen oder benignen Grunderkrankung. Akanthosis nigricans bezeichnet eine Gruppe klinisch ähnlicher Hauterkrankungen, die durch meist symmetrisch vorkommende, schmutzig braune bis graue warzenartige Hautveränderungen gekennzeichnet sind. Die Hautveränderungen finden sich vorwiegend in den Achselhöhlen, Gelenkbeugen, im Nacken oder in den Leistenbeugen [122]. Die Akanthosis nigricans maligna ist die paraneoplastisch vorkommende Form. Es existieren Fallbeschreibungen einer Akanthosis nigricans beim pulmonalen Adenokarzinom, beim Plattenepithelkarzinom der Lunge und beim bronchoalveolären Karzinom [123 - 125]. Die Pathogenese der Akanthosis nigricans maligna ist ungeklärt. Wachstumsfaktoren wie beispielsweise Transforming growth factor (TGF)- $\alpha$ könnten eine wichtige Rolle bei der Hyperplasie und Hyperpigmentation spielen [126]. TGF- $\alpha$ wird von malignen Zellen gebildet und bindet an den Epidermal-growth-factor-Rezeptor (EGFR), der von Tumorzellen exprimiert wird. TGF- $\alpha$ und EGFR fördern über auto- und parakrine Sekretion die Tumorprogression [127]. Neben der Expression in Tumorzellen wird EGFR auch in normalen Keratinozyten exprimiert, insbesondere in den proliferierenden Zellen der basalen Hautschichten.

Die palmoplantare Hyperkeratose (auch als Tylosis bezeichnet) ist sehr selten. In der Literatur finden sich im Wesentlichen Fallbeschreibungen [128-130]. Die palmoplantare Hyperkeratose geht der Tumordiagnose oft Monate bis Jahre voraus [131]. Die Prognose von Krebspatienten mit einer palmoplantaren Hyperkeratose ist schlecht [129].

Ein anderes seltenes, aber klinisch bedeutsames kutanes paraneoplastisches Syndrom ist die Akrokeratitis paraneoplastica (Bazex-Syndrom). Sie wurde erstmals 1965 von Bazex und Mitarbeitern beschrieben [132]. Es handelt sich um papulosquamöse Läsionen, Hyperpigmentation, Keratoderm, Paronychie und Nageldystrophie [133]. Obwohl das Syndrom äußerst selten auftritt, ist es klinisch wichtig, da die Hautsymptome der Tumormanifestation in der Mehrzahl der Fälle um Monate vorausgehen, sodass nach der Diagnosestellung eines Bazex-Syndroms eine 
Suche nach einem okkulten Tumor durchgeführt werden sollte. Darüber hinaus ist die Akrokeratitis paraneoplastica ein Marker für ein supra-diaphragmales Malignom [134].

\section{Kachexie}

Kachexie ist wahrscheinlich eine der häufigsten klinischen Manifestationen einer fortgeschrittenen Krebserkrankung. Sie kommt in ca. $50 \%$ der Fälle vor und ist für ungefähr $25 \%$ aller krebsbedingten Todesfälle verantwortlich [135]. Die Ausprägung der Kachexie ist umgekehrt proportional zur Überlebenszeit und weist auf eine schlechte Prognose hin. In vielen Fällen tritt eine Kachexie erst in späten Stadien beim Vorliegen von Fernmetastasen auf. Es gibt jedoch auch Krankheitsverläufe, in denen sich eine Kachexie wesentlich früher manifestiert, sodass sie durchaus als paraneoplastisches Syndrom aufgefasst werden kann.

Die Kachexie umfasst Anorexie, Gewichtsverlust, Verlust an Muskelmasse, Anämie sowie Störungen im Kohlenhydrat-, Eiweißund Fettstoffwechsel. Die Anorexie und die metabolischen Störungen machen den wesentlichen Anteil der Kachexie aus. Krebspatienten weisen oft eine relative Glukoseintoleranz und Insulinresistenz auf. Der Verlust von Fettgewebe beruht wahrscheinlich auf einer verminderten Liponeogenese. Die Lipolyse ist nicht signifikant gesteigert. Häufig lässt sich ein Verlust von Muskelproteinen und eine verminderte Synthese muskulärer Proteine bei Kachexie nachweisen $[136,137]$. Die Proteinsynthese in der Leber ist im Sinne einer akuten Phase-Reaktion verändert wie sie auch bei Traumen, Entzündungen oder Infektionen auftritt. Bei einem großen Teil von Patienten mit einem Lungenkarzinom finden sich vermehrt akute Phase-Proteine. Es besteht eine Korrelation zwischen akuter Phase-Reaktion und Gewichtsverlust bei Lungenkrebs [138]. Daneben sind eine ganze Reihe von Mediatoren beschrieben worden, die eine Rolle bei der Entwicklung einer Kachexie spielen [139]. Der Tumor verhält sich wie ein neues, metabolisch aktives Organ. Es ist aber unklar, ob die Mediatoren vom Tumor selbst oder vom Organismus freigesetzt werden [139-141].

Anorexie entsteht u.a. über die Unfähigkeit des Hypothalamus, adäquat auf Signale zu reagieren, die ein Energiedefizit anzeigen. Generell vermindern serotoninerge Signale im Hypothalamus den Appetit. Bei Krebspatienten sind die Konzentrationen von freiem Tryptophan, dem Vorläufer von Serotonin, erhöht [142]. Ein anderer möglicher Mechanimus, über den die Fähigkeit des Hypothalamus, adäquat auf Hungerreize zu reagieren, gehemmt wird, ist die Inhibierung von Neuropeptid Y (das die Nahrungsaufnahme stimuliert) durch Zytokine wie beispielsweise IL-1 und TNF- $\alpha$. Zumindest Daten im Tiermodell sprechen für diese Hypothese [143]. Es sind auch Veränderungen in Hormonspiegeln und Zielorgansensitivitäten bei Malignomen beschrieben worden. So können erhöhte Kortisol- und Glukagonkonzentrationen die akute Phase-Reaktionsantwort verstärken [144,145]. Eine wichtige Rolle in der Entwicklung der Kachexie spielen sicher auch proinflammatorische Zytokine wie TNF- $\alpha$, IL-1, IL-6 und IFN- $\gamma$ sowie ciliärer neurotroper Faktor (CNTF) [135]. Diese Zytokine hemmen u. a. die Lipoproteinlipase und verhindern auf diese Weise die Speicherung von Fettsäuren in Adipozyten. Neben den Zytokinen des Organismus produziert der Tumor aber auch selbst Mediatoren wie beispielsweise Proteolysis-inducing factor (PIF) und Lipid mobilizing factor (LMF) [146, 147].

Es gibt derzeit keine spezifische und effektive Therapie der Malignom-bedingten Kachexie. Eine gesteigerte Nahrungsaufnahme zur Behebung der Malnutrition ist durch das Protein-Energie-Defizit und das „Wasting“ sowie die Anorexie und das frühe Sätti- gungsgefühl kaum möglich. Eine ganze Reihe von Substanzen ist eingesetzt worden, um den gestörten Metabolismus zu reparieren. Kortikosteroide sind und werden am häufigsten benutzt, haben aber nur einen kurzzeitigen Effekt. Ibuprofen hat eine gewisse Wirkung aufgrund seiner antiinflammatorischen Eigenschaften. Medroxyprogesteronazetat kann den Appetit steigern und das Gewicht stabilisieren. Eicosapentaensäure kann die Bildung von proinflammatorischen Zytokinen vermindern [4].

\section{Fatigue}

Bis zu 90\% aller Malignompatienten geben Fatigue-Symptome an, wohingegen die Prävalenzraten in Studien bei 60\% liegen [148]. Fatigue ist ein sehr subjektiv erlebter multidimensionaler Zustand. Patienten mit Fatigue berichten von physikalischer Erschöpfung, verminderter körperlicher Aktivität, fehlender Motivation und/oder mentaler Erschöpfung [149]. Fatigue kann sowohl durch die Krebserkrankung als auch durch die Behandlung bedingt sein. Die Basismechanismen der Fatigue lassen sich grob in zwei Hauptkomponenten aufteilen: peripher und zentral. Die periphere Fatigue betrifft die neuromuskulären Verbindungen und die Muskulatur. Dies führt dazu, dass das periphere neuromuskuläre System nicht mehr auf zentrale Stimuli reagiert. Die zentrale Fatigue entsteht durch die progressive Abnahme der Impulsübertragung von Motorneuronen. Daraus resultieren Schwierigkeiten, willentlich Handlungen zu initiieren oder aufrechtzuerhalten $[150,151]$.

Die Ätiologie der Fatigue ist bisher nur schlecht verstanden. Es sind eine ganze Reihe pathophysiologischer Mechanismen vorgeschlagen worden. Allerdings basieren diese auf Studien an gesunden Probanden nach Belastung oder bei chronischen Erkrankungen wie beispielsweise dem Fatigue-Syndrom im Rahmen der rheumatoiden Arthritis [152].

Es sind verschiedene pathophysiologische Veränderungen bei der Malignom-induzierten Fatigue beschrieben worden. Patienten mit chronischer Fatigue haben offenbar erhöhte Plasmaspiegel an freiem Tryptophan, was möglicherweise zu erhöhten Serotonin-Konzentrationen im ZNS führt [153,154]. Ein Anstieg von Serotonin (5-HT)-Spiegeln im Gehirn und/oder eine Vermehrung von 5-HT-Rezeptoren kann möglicherweise zu einer verminderten sensomotorischen Aktivität („sensomotor drive“) führen und dem Eindruck einer reduzierten Kapazität für physikalische Aktivität [155]. Es sind auch erniedrigte Kortisolspiegel bei Patienten mit chronischer Fatigue beobachtet worden, was für eine Beteiligung der Hypothalamus-Hypophysen-Achse bei Fatigue spricht [156]. Ein anderer wichtiger pathophysiologischer Prozess im Rahmen der Fatigue ist offenbar die Störung der zirkadianen Rhythmik durch den Krebs. Hierunter fallen Störungen der endokrinologischen Rhythmik (z. B.: Kortisol-, Melatonin- und Prolaktinsekretion), der metabolischen Prozesse (z.B.: Körpertemperatur und Proteinkonzentrationen), des Immunsystems (z.B.: Anzahl zirkulierender Leukozyten und neurophiler Granulozyten) und der Aktivitäts-Inaktivitäts-Muster [157-161]. Tumoren beeinträchtigen darüber hinaus die Fähigkeit der Skelettmuskulatur ATP (Adenosintriphosphat) zu regenerieren, sodass die Leistungsfähigkeit eingeschränkt wird [155]. So sind ein reduzierter oxidativer Stoffwechsel, vermindertes intrazelluläres ATP in Verbindung mit einer Dysregulation des 2',5'-Oligoadenylatsynthetase/RNase L-Wegs und eine gestörte ATP-Synthese beschrieben worden [162 -164]. Bei vielen Mechanismen, die als relevant für die Entstehung einer Fatigue-Symptomatik angesehen werden, spielen proinflammatorische Zytokine wie das IL-1 oder TNF- $\alpha$ eine wichtige Rolle [165]. 
Tab. 2 Häufige paraneoplastische Syndrome: Ätiologie, klinische Symptomatik und Therapie.

\begin{tabular}{|c|c|c|c|}
\hline Syndrom & Auftreten bei & Symptome & Therapie* \\
\hline Hyperkalziämie & $\begin{array}{l}\text { v.a. NSCLC } \\
\text { (PEC, Adeno) }\end{array}$ & $\begin{array}{l}\text { Anorexie, Nausea, Erbrechen, Polyurie, } \\
\text { Polydipsie }\end{array}$ & forcierte Diurese, Biphosphonate \\
\hline SIADH & v.a. SCLC & $\begin{array}{l}\text { Hyponatriämie, Anorexie, Übelkeit, Erbrechen, } \\
\text { Verwirrungszustände, Krämpfe, Somnolenz, } \\
\text { Koma }\end{array}$ & $\begin{array}{l}\text { Flüssigkeitsrestriktion, hypertone Kochsalz- } \\
\text { lösung, Vaptane }\end{array}$ \\
\hline $\begin{array}{l}\text { EAS/Cushing- } \\
\text { Syndrom }\end{array}$ & $\begin{array}{l}\text { EAS: } \\
\text { v. a. Bronchuskarzinoid } \\
\text { Cushing-Syndrom: } \\
\text { v.a.SCLC }\end{array}$ & $\begin{array}{l}\text { periphere Ödeme, proximale Myopathie, Voll- } \\
\text { mondgesicht, Gewichtsverlust, hypokaliämische } \\
\text { Alkalose, Hyperglykämie }\end{array}$ & Therapie der Grundkrankheit \\
\hline Anämie & beide & Blässe, Dyspnoe, verminderte Belastbarkeit & Transfusion, Erythropoetin \\
\hline LEMS & v.a. SCLC & $\begin{array}{l}\text { progrediente Muskelschwäche der proximalen } \\
\text { unteren Extremitäten, Fatigue, Mundtrocken- } \\
\text { heit, Ptosis }\end{array}$ & $\begin{array}{l}\text { 3,4-Diaminopyridin, intravenöse Immun- } \\
\text { globulingabe }\end{array}$ \\
\hline $\begin{array}{l}\text { Akanthosis } \\
\text { nigricans }\end{array}$ & v. a. NSCLC & $\begin{array}{l}\text { warzenartige Hautveränderungen (Achsel- } \\
\text { höhlen, Gelenkbeugen, im Nacken oder in den } \\
\text { Leistenbeugen) }\end{array}$ & keine spezifische \\
\hline Dermatomyositis & v.a. SCLC & proximale Myopathie, Erytheme & Glukokortikosteroide \\
\hline Thrombembolie & beide & $\begin{array}{l}\text { Thrombosezeichen, Dyspnoe, thorakale } \\
\text { Schmerzen, Hämoptysen }\end{array}$ & Antikoagulation \\
\hline $\begin{array}{l}\text { Trommelschlegel- } \\
\text { finger/HPO }\end{array}$ & $\begin{array}{l}\text { v. a. NSCLC } \\
\text { (PEC, Adeno) }\end{array}$ & nicht-steroidale Antiphlogistika, Biphosphonate & $\begin{array}{l}\text { Schwellung der terminalen Phalangen, schmerz- } \\
\text { hafte symmetrische Arthropathie (Sprung- und } \\
\text { Hüftgelenke), periostale Knochenneubildung an } \\
\text { den distalen Extremitäten }\end{array}$ \\
\hline Kachexie & beide & $\begin{array}{l}\text { Gewichtsverlust, Anorexie, Verlust an Muskel- } \\
\text { masse, Anämie }\end{array}$ & $\begin{array}{l}\text { Ibuprofen, Medroxyprogesteronazetat, } \\
\text { Eicosapentaensäure }\end{array}$ \\
\hline Fatigue & beide & $\begin{array}{l}\text { physikalische Erschöpfung, verminderte } \\
\text { körperliche Aktivität, fehlende Motivation, } \\
\text { mentale Erschöpfung }\end{array}$ & $\begin{array}{l}\text { Antidepressiva, Kortikosteroide, Psycho- } \\
\text { stimulantien, Modafinil }\end{array}$ \\
\hline
\end{tabular}

* Es ist die spezifische Therapie für das jeweilige Syndrom angeführt (sofern bekannt).

NSCLC: non-small cell lung cancer. SCLC: small cell lung cancer. PEC: Plattenepithelkarzinom. Adeno: Adenokarzinom.

Es gibt keine generellen Therapieempfehlungen für die Fatigue. Die Behandlung sollte sich immer an der individuellen Situation und zugrunde liegenden Pathologie orientieren. Neben Antidepressiva, Kortikosteroiden und Psychostimulantien bietet Modafinil eine neue therapeutische Alternative.

\section{Therapie}

Die aktuelle S3-Leitlinie zur Prävention, Diagnostik, Therapie und Nachsorge des Lungenkarzinoms empfiehlt grundsätzlich keinen Patienten mit paraneoplastischen Syndromen aufgrund der Symptome von einem potenziell kurativen Therapieansatz auszuschließen [58]. Die Therapie der paraneoplastischen Syndrome richtet sich nach der jeweiligen Symptomatik und ist in den einzelnen Abschnitten näher beschrieben. Die Therapie der Grunderkrankung ist unverzichtbarer Bestandteil und erster Schritt in der Therapie. Tab. 2 gibt eine Kurzübersicht über die wichtigsten paraneoplastischen Syndrome und die möglichen Therapieoptionen beim Lungenkarzinom.

\section{Interessenkonflikt}

$\nabla$

Der Autor gibt an, dass kein Interessenkonflikt besteht.

\section{Literatur}

1 Bunn PA, Ridgway EC. Paraneoplastic syndromes. In: DeVita VT et al. eds. Cancer: Principles and Practice of Oncology. 4th edn. Philadelphia: Lippincott Co 1993: 2026-2071

2 Navani N, Spiro SG. Symptoms and signs of lung cancer. In: Spiro SG, Huber RM, Janes SM, eds. Thoracic Malignancies. Eur Respir Monograph 2009; 44: $71-87$

3 Richardson GE, Johnson BE. Paraneoplastic syndromes in lung cancer Curr Opin Oncol 1992; 4: 323-333

4 Heinemann S, Zabel P, Hauber HP. Paraneoplastic syndromes in lung cancer. Cancer Therapy 2008; 6: 687-698

5 Monsieur I, Meysman M, Noppen N et al. Non-small-cell lung cancer with multiple paraneoplastic syndromes. Eur Respir J 1995; 8: 1231 1234

6 Spiro SG, Gould MK, Colice GL. Initial evaluation of the patient with lung cancer: symptoms, signs, laboratory tests, and paraneoplastic syndromes. ACCP evidence-based clinical practice guidelines (2nd edition). Chest 2007; 132: 149S-160S

7 Hiraki A, Ueoka H, Takata I et al. Hypercalcemia-leukocytosis syndrome associated with lung cancer. Lung Cancer 2004; 43: 301 - 307

8 Burtis WJ, Brady TG, Orloff JJ et al. Immunochemical characterization of circulating parathyroid hormone-related protein in patients with hypercalcemia of cancer. N Engl J Med 1990; 322: 1106-1112

9 Moseley JM, Kubota M, Diefenbach-Jagger $H$ et al. Parathyroid hormone-related protein purified from a human lung cancer cell line. Proc Natl Acad Sci 1987; 84: 5048-5052

10 Abou-Samra AB, Juppner H, Force T et al. Expression cloning of a common receptor for parathyroid hormone and parathyroid hormonerelated peptide from rat osteoblast-like cells: a single receptor stimulates intracellular accumulation of both cAMP and inositol trisphosphates and increases intracellular free calcium. Proc Natl Acad Sci 1992; 89: 2732-2736

11 Horiuchi N, Caulfield MP, Fisher JE et al. Similarity of synthetic peptide from human tumor to parathyroid hormone in vivo and in vitro. Science 1987; 238: 1566-1568 
12 Danks JA, Ebeling PR, Hayman J et al. Parathyroid hormone-related protein: immunohistochemical localization in cancers and in normal skin. J Bone Min Res 1989; 4: 273-278

13 Asa SL, Henderson J, Goltzman D, Drucker DJ. Parathyroid hormonelike peptide in normal and neoplastic human endocrine tissues. J Clin Endocrinol Metab 1990; 71: $1112-1118$

14 Clines GA, Guise TA. Hypercalcaemia of malignancy and basic research on mechanisms responsible for osteolytic and osteoblastic metastasis in bone. Endocr Rel Cancer 2005; 12: 549 - 583

15 Juppner H, Abou-Samara AB, Freeman $M$ et al. A G protein-linked receptor for parathyroid hormone and parathyroid hormone-related peptide. Science 1991; 254: 1024-1026

16 Mahon MJ, Donowitz M, Yun CC, Segre GV. $\mathrm{Na}(+) / \mathrm{H}(+)$ exchanger regulatory factor 2 directs parathyroid hormone 1 receptor signalling. Nature 2002; 417: 858-861

17 Swarthout JT, D'Alonzo RC, Selvamurugan N, Partridge NC. Parathyroid hormone-dependent signalling pathways regulating genes in bone cells. Gene 2002; 282: 1 - 17

18 Luparello C, Burtis WJ, Raue F et al. Parathyroid hormone-related peptide and 8701-BC breast cancer cell growth and invasion in vitro: evidence for growth-inhibiting and invasion-promoting effects. Mol Cell Endocrinol 1995; 111: 225-232

19 Luparello C, Ginty AF, Gallagher JA et al. Transforming growth factorbeta 1 , beta 2 , and beta 3 , urokinase and parathyroid hormone-related peptide expression in 8701-BC breast cancer cells and clones. Differentiation 1993; 55: $73-80$

$20 \mathrm{Li} \mathrm{H}$, Seitz PK, Selvanayagam P et al. Effect of endogenously produced parathyroid hormone-related peptide on growth of a human hepatoma cell line (Hep G2). Endocrinol 1996; 137: 2367 - 2374

21 Chen HL, Demiralp B, Schneider A et al. Parathyroid hormone and parathyroid hormone-related protein exert both pro- and anti-apoptotic effects in mesenchymal cells. J Biol Chem 2002; 277: 1937419381

22 Yoshimoto K, Yamasaki R, Sakai H et al. Ectopic production of parathyroid hormone by small cell lung cancer in a patient with hypercalcemia. J Clin Endocrinol Metabol 1989; 68: 976-981

23 Nielsen PK, Rasmussen AK, Feldt-Rasmussen Um Brandt M et al. Ectopic production of intact parathyroid hormone by a squamous cell lung carcinoma in vivo and in vitro. J Clin Endocrinol Metabol 1996; 81: $3793-3796$

24 Seymour JF, Gagel RF, Hagemeister FB et al. Calcitriol production in hypercalcemic and normocalcemic patients with non-Hodgkin lymphoma. Ann Intern Med 1992; 121: 633 - 640

25 Mawer EB, Hayes ME, Heys SE et al. Constitutive synthesis of 1,25-dihydroxyvitamin D3 by human small cell lung cancer cell line. J Clin Endocrinol Metabol 1994; 79: 554 - 560

26 Bertolini DR, Nedwin GE, Bringman TS et al. Stimulation of bone resorption and inhibition of bone formation in vitro by human tumor necrosis factors. Nature 1986; 319: $516-518$

27 Yates AJ, Boyce BF, Favarato G et al. Expression of human transforming growth factor alpha by Chinese hamster ovarian tumors in nude mice causes hypercalcemia and increased osteoclastic bone resorption. J Bone Min Res 1992; 7: 847-853

28 Ibbotson KJ, Twardzik DR, D'Souza SM et al. Stimulation of bone resorption in vitro by synthetic transforming growth factor-alpha. Science 1995; 228: 1007 - 1009

29 Bender RA, Hansen $H$. Hypercalcemia in bronchogenic carcinoma. Ann Intern Med 1974; 80: 205 - 208

30 Bethune JE, Turpin RA. A study of urinary excretion of parathyroid hormone in man. J Clin Invest 1968; 47: 1583-1589

31 Thomas L, Kwok Y, Edelman MJ. Management of paraneoplastic syndromes in lung cancer. Curr Opin Pulm Med 2007; 13: 362 - 367

32 List AF, Hainsworth JD, Davis BW et al. The syndrome of inappropriate secretion of antidiuretic hormone (SIDAH) in small-cell lung cancer. J Clin Oncol 1986; 4: 1191-1198

33 Patel AM, Davila DG, Peters SG. Paraneoplastic syndromes associated with lung cancer. Mayo Clin Proc 1993; 68: 278-287

34 Maurer LH, O'Donnell JF, Kennedy S et al. Human neurophysins in carcinoma of the lung. Cancer Treat Rep 1994; 79: 971 - 976

35 Bliss DP Jr., Battey JF, Linnoila RI et al. Expression of atrial natriuretic factor gene in small lung cancer tumors and tumor cell lines. J Natl Cancer Inst 1990; 82: $305-310$

36 Moses AM, Scheinman SJ. Ectopic secretion of neurophyseal peptides in patients with malignancy. Endocrinol Metab Clin North Am 1991; 20: $489-506$
37 Hansen $\mathrm{O}$, Sorensen $\mathrm{P}$, Hansen $\mathrm{KH}$. The occurence of hyponatremia in SCLC and the influence on prognosis: a retrospective study of 453 patients treated in a single institution in a 10-year period. Lung Cancer 2010; 68: $111-114$

38 Vorherr $H$. Para-endocrine tumor activity with emphasis on ectopic ADH secretion. Oncology 1974; 29: 382-416

39 Nielsen S, Frokiaer J, Marples D et al. Aquaporins in the kidney: from molecule to medicine. Physiol Rev 2002; 82: 205-244

40 Jaenike JR, Waterhouse $C$. The renal response to sustained administration of vasopressin and water in man. J Clin Endocrinol Metab 1961; 21: $231-242$

41 Hannon MJ, Thompson CJ. The syndrome of inappropriate antidiuretic hormone: prevalence, causes, and consequences. Eur J Endocrinol 2010; 162: S5 - S12

42 Schrier RW, Gross P, Gheorghiade $M$ et al. Tolvaptan, a selective oral vasopressin V2-receptor antagonist, for hyponatremia. N Engl J Med 2006; 355: 2099-2112

43 Mendelsohn G, Baylin SB. Ectopic hormone production: biological and clinical implications. Prog Clin Biol Res 1984; 142: 291 - 316

44 Hansen $M$. Paraneoplastic syndromes and tumor markers for smallcell and non-small-cell lung cancer. Curr Opin Oncol 1990; 2: 345 351

45 Mennecier B, Moreau L, Goichot B, Quoix E. Paraneoplastic Cushing's syndrome and small cell bronchial carcinoma. Rev Pneumol Clin 1999; 55: $77-80$

46 Shepherd FA, Laskey J, Evans WK et al. Cushing's syndrome associated with ectopic corticotropin production and small-cell lung cancer. J Clin Oncol 1992; 10: $21-27$

47 Terzolo M, Reimondo G, Ali A et al. Ectopic ACTH syndrome: molecular bases and clinical heterogeneity. Ann Oncol 2001; 12 (Suppl): S83S87

48 Odell WD, Wolfesen AR, Bachelot I, Hirose FM. Ectopic production of lipotropin by cancer. Am J Med 1979; 66: 631 - 638

49 Oliver RL, Davis JR, White A. Characterization of ACTH related peptides in ectopic Cushing's syndrome. Pituitary 2003; 6: 119-126

50 Stewart MF, Crosby SR, Gibson S et al. Small cell lung cancer cell lines secrete predominantly ACTH precursor peptides not ACTH. Br J Cancer 1989; 60: 20-24

51 White A, Stewart MF, Farrell WE et al. Proopiomelanocortin gene expression and peptide secretion in human small-cell lung cancer cell lines. J Mol Endocrinol 1989; 3: 65 - 70

52 Crosby SR, Stewart MF, Farrell WE et al. Comparison of ACTH and ACTH precursor peptides secreted by human pituitary and lung tumour cells in vitro. J Endorcinol 1990; 125: 147-152

53 Kosmidis P, Krzakowski M. Anemia profiles in patients with lung cancer: what have we learned from the European Cancer Anemia Survey (ECAS)? Lung Cancer 2005; 50: $401-412$

54 Glaspy J, Degos L, Dicato M, Demetri GD. Comparable efficacy of epoetin alfa for anemic cancer patients receiving platinum- and nonplatinum-based chemotherapy: A retrospective subanalysis of two large, community-based trials. The Oncologist 2002; 7: 126-135

55 Groopman JE, Itri LM. Chemotherapy-induced anemia in adults: incidence and treatment. J Natl Cancer Inst 1999; 91: 1616-1634

56 Bohlius J, Schmidlin K, Brillant C et al. Erythropoetin or darbepoetin for patients with cancer - meta-analysis based on individual patient data. Cochrane Database Syst Rev 2009; 3: CD007303

57 Glaspy J, Crawford J, Vansteenkiste J et al. Erythropoiesis-stimulating agents in oncology: a study-level meta-analysis of survival and other safety outcomes. Br J Cancer 2010; 102: 301 - 315

58 Goeckenjan G, Sitter H, Thomas $M$ et al. Prävention, Diagnostik, Therapie und Nachsorge des Lungenkarzinoms. Interdisziplinäre S3-Leitlinie der Deutschen Gesellschaft für Pneumologie und Beatmungsmedizin und der Deutschen Krebsgesellschaft. Pneumologie 2010; 64 (Suppl. 2): S23-S155

59 Asano S, Urabe A, Okabe T et al. Demonstration of granulopoetic factors in the plasma of nude mice transplanted with a human lung cancer and in the tumor tissue. Blood 1977; 49: 845-852

60 Sawyers CL, Golde DW, Quan S, Nimer SD. Production of granulocytemacrophage colony stimulating factor in two patients with lung cancer, leukocytosis and eosinophilia. Cancer 1992; 69: 1342 - 1346

61 Matsuguchi T, Okamura S, Kawasaki C et al. Constitutive production of granulocyte colony-stimulating factor and interleukin- 6 by a human lung cancer cell line, KSNY: gene amplification and increased mRNA stability. Eur J Haematol 1991; 47: 128-133 
62 Tesselaar ME, Osanto S. Risk of venous thromboembolism in lung cancer. Curr Opin Pulm Med 2007; 13: 362-367

63 Chew HK, Davies AM, Wun T et al. The incidence of venous thromboembolism among patients with lung cancer.J Thromb Haemost 2008; 6: $601-608$

64 Girard P, Raynaud C, Meyer G et al. Thrombosis and lung cancer. Rev Pneumol Clin 2008; 64: 85-91

65 Molnar S, Guglielmone H, Lavarda M et al. Procoagulant factors in patients with cancer. Hematology 2007; 12: 555-559

66 Goldin-Lang P, Tran QV, Fichtner I et al. Tissue factor expression pattern in human non-small cell lung cancer tissues indicates increased blood thrombogenicity and tumour metastasis. Oncol Rep 2008; 20: $123-138$

67 Akl EA, Rohilla S, Barba M et al. Anticoagulation for the initial treatment of venous thromboembolism in patients with cancer. Cochrane Database Syst Rev 2008; 23: CD006649

68 Akl EA, Kamath G, Kim SY et al. Oral anticoagulation for prolonging survival in patients with cancer. Cochrane Database Syst Rev 2007; 18: CD006466

69 Nalluri SR, Chu D, Keresztes R et al. Risk of venous thromboembolism with angiogenesis inhibitor bevacizumab in cancer patients: a metaanalysis. JAMA 2008; 300: 2277-2285

70 Hicks LK, Cheung MC, Ding $K$ et al. Venous thromboembolism and nonsmall cell lung cancer: a pooled analysis of National Cancer Institute of Canada Clinical Group trials. Cancer 2009; 115: 5516- 5525

71 Sridhar KS, Lobo CF, Altman RD. Digital clubbing and lung cancer. Chest 1998; 114: 1535-1537

72 Stenseth JH, Clagett OT, Woolner LB. Hypertrophic pulmonary osteoarthropathy. Dis Chest 1967; 52: 62 - 68

73 Prakash $U$. Hypertrophic pulmonary osteoarthropathy and clubbing. In: Sackner MA, ed. Weekly updates: pulmonary medicine; lesson 30 Princeton, NJ: Biomedia 1978: 2-7

74 Myers KA, Farquhar DER. Does this patient have clubbing? JAMA 2001; 286: $341-347$

75 Shneerson JM. Digital clubbing and hypertrophic osteoarthropathy. $\mathrm{Br}$ J Dis Chest 1981; 75: 113-131

76 Atkinson S, Fox SB. Vascular endothelial growth factor (VEGF)-A and platelet-derived growth factor (PDGF) play a central role in the pathogenesis of digital clubbing. J Pathol 2004; 203: 721 - 728

77 Olan F, Portela $M$, Navarro $C$ et al. Circulating vascular endothelial growth factor concentrations in a case of pulmonary hypertrophic osteoarthropathy. J Rheumatol 2004; 31: 614-616

78 Silveira LH, Martínez-Lavín M, Pineda C et al. Vascular endothelial growth factor and hypertrophic osteoarthropathy. Clin Exp Rheumatol 2000; 18: 57-62

79 Pracht M, LeRoux C, Kerjouan M et al. Clubbing and hypertrophic osteoarthropathy in two patients taking long-term bevacizumab for metastatic colorectal cancer. J Gastrointest Cancer 2010 [epub ahead of print May 28, 2010]

80 Uppal S, Diggle CP, Carr IM et al. Mutations in 15-hydroxyprostaglandin dehydrogenase cause primary hypertrophic osteoarthropathy. Nat Genet 2008; 40: 789-793

81 Amital H, Applbaum YH, Vasiliev L, Rubinow A. Hypertrophic pulmonary osteoarthropathy: control of pain and symptoms with pamidronate. Clin Rheumatol 2004; 23: 330-332

82 Hill CL, Zhang Y, Sigugeirsson B et al. Frequency of specific cancer types in dermatomyositis and polymyositis: a population-based study. Lancet 2001; 357: 96-100

83 Fujita J, Tokuda M, Bandoh S et al. Primary lung cancer associated with polymyositis/dermatomyositis, a review of the literature. Rheumatol Int 2001; 20: $81-84$

84 Yang Y, Fujita J, Tokuda $M$ et al. Lung cancer associated with several connective tissue diseases: a review of the literature. Rheumatol Int 2001; 21: 106-113

85 Casciola-Rosen L, Nagaraju K, Plotz P et al. Enhanced autoantigen expression in regenerating muscle cells in idiopathic inflammatory myopathy. J Exp Med 2005; 201: 591 -601

86 Krathen MS, Fiorentino D, Werth VP. Dermatomyositis. Curr Dis Autoimmun 2008; 10: 313-323

87 Levine SM. Cancer and myositis: new insights into an old association. Curr Opin Rheumatol 2006; 18: 620-624

88 Iorizzi LJ 3rd, Jorizzo JL. The treatment and prognosis of dermatomyositis: an updated review. J Am Acad Dermatol 2008; 59: 99-112
89 Mollina-Garrido MJ, Guillen-Ponce C, Martinez S, Guirado-Risueno M. Diagnosis and current treatment of neurological paraneoplastic syndromes. Clin Transl Oncol 2006; 8: 796-801

90 Swash M, Schwartz MS. Paraneoplastic syndromes. In: Johnson RT, eds. Current therapy of neurologic disease. Philadelphia, PA: BC Decker 1990: 236-243

91 Elrington GM, Murray NMF, Spiro SG, Newsom-Davis J. Neurological paraneoplastic syndromes in patients with small cell lung cancer: a prospective survey of 150 patients. J Neurol Neurosurg Psychiatry 1991; 54: $764-767$

92 Seute T, Leffers P, ten Velde GPM, Twiynstra A. Neurologic disorders in 432 consecutive patients with small cell lung carcinoma. Cancer 2004; 100: $801-806$

93 Martina T, Clay AS. A 50-year-old woman with bilateral vocal cord paralysis and hilar mass. Chest 2005; 128: 1028 - 1031

94 Anderson NE, Rosenblum MK, Graus F et al. Autoantibodies in paraneoplastic syndromes associated with small-cell lung cancer. Neurology 1988; 38: $1391-1398$

95 Szabo A, Dalmau J, Manley G et al. HuD, a paraneoplastic encephalomyelitis antigen, contains RNA-binding domains and is homologous to Elva and sex-lethal. Cell 1991; 67: 325 - 333

96 King PH, Dropcho EJ. Expression of Hel-N1 and Hel-N2 in small-cell lung carcinoma. Ann Neurol 1996; 39: 679-681

97 Darnell RB, Posner JB. Paraneoplastic syndromes involving the nervous system. N Engl J Med 2003; 349: 543-1554

98 Sillevis Smitt PA, Manley GT, Posner JB. Immunization with the paraneoplastic encephalomyelitis antigen HuD does not cause neurologic disease in mice. Neurology 1995; 45: 1873-1878

99 Carpentier AF, Rosenfeld MR, Delattre JY et al. DNA vaccination with HuD inhibits growth of neuroblastoma in mice. Clin Cancer Res 1998; 4: $2819-2824$

100 Posner JB, Dalmau J. Paraneoplastic syndromes. Curr Opin Immunol 1997; 9: $723-729$

101 Molinuevo JL, Graus F, Serrano C et al. Utility of anti-Hu antibodies in the diagnosis of paraneoplastic sensory neuropathy. Ann Neurol 1998; 44: 976-980

102 Dalmau J, Graus F, Rosenblum MK et al. Anti-Hu-associated paraneoplastic encephalomyelitis/sensory neuropathy. Medicine 1992; 71 : 9-72

103 Graus F, Keine-Gribert F, Rene R et al. Anti-Hu-associated paraneoplastic encephalomyelitis: analysis of 200 patients. Brain 2001; 124: $1138-1148$

104 Spiegelman D, Maurer $\mathrm{LH}$, Ware JH et al. Prognostic factors in smallcell carcinoma of the lung: an analysis of 1521 patients. J Clin Oncol 1989; 7: $344-354$

105 Anderson NE, Budde-Steffen C, Rosenblum MK et al. Opsoclonus, myoclonus, ataxia, and encephalopathy in a adults with cancer: a distinct paraneoplastic syndrome. Medicine (Baltimore) 1988; 67: 100 - 109

106 Bataller L, Graus F, Saiz A, Vilchez JJ and for the Spanish OpsoclonusMyoclonus Study Group. Clinical outcome in adult onset idiopathic or paraneoplastic opsoclonus-myoclonus. Brain 2001; 124: 437-443

107 Margery J, Ferroir JP, Epaud C et al. Paraneoplastic opsoclonus-myoclonus syndrome associated with small-cell lung cancer. Rev Pneumol Clin 2003; 59: 321 - 324

108 Hassan KA, Kalemkerian GP, Trobe JD. Long-term survival in paraneoplastic opsoclonus-myoclonus syndrome associated with small cell lung cancer. J Neuroophthalmol 2008; 28: $27-30$

109 Lennon VA, Kryzer TJ, Greismann GE et al. Calcium-channel antibodies in the Lambert-Eaton syndrome and other paraneoplastic syndromes. New Engl J Med 1995; 332: 1467 - 1474

110 Mareska M, Gutmann L. Lambert-Eaton myasthenic syndrome. Semin Neurol 2004; 24: 149-153

111 Maddison P, Lang B. Paraneoplastic neurological autoimmunity and survival in small-cell lung cancer. J Neuroimmunol 2008; 201: 159162

112 Henson RA, Ulrich $H$. Encephalomyelitis with carcinoma. In: Henson RA, Ulrich H, eds. Cancer and the nervous system. Oxford: Blackwell Scientific 1982: $314-345$

113 Graus F, Cordon-Cardo C, Posner JB. Neuronal antinuclear antibody in sensory neuronopathy from lung cancer. Neurology 1985; 35: 538 543

114 Graus F, Elkon KB, Cordon-Cardo C, Posner JB. Sensory neuronopathy and small cell lung cancer. Antineuronal antibody that also reacts with the tumor. Am J Med 1986; 80: 45-52 
115 Clamno GH, Evans WK, Shepherd FA et al. Myasthenic syndrome and small cell cancer of the lung. Arch Intern Med 1984; 144: 999-1000

116 Dropcho EJ. Autoimmune central nervous system paraneoplastic disorders. Ann Neurol 1995; 37: S102-S113

117 Maddison P, Newsom-Davis J. Treatment for Lambert-Eaton myasthenic syndrome. Cochrane Database Syst Rev 2005; 18: CD003279

118 Quartel A, Turbeville S, Lounsbury D. Current therapy for Lambert-Eaton myasthenic syndrome: development of 3,4-diaminopyridine phosphate salt as first-line symptomatic treatment. Curr Med Res Opin 2010; 26: $1363-1375$

119 Keime-Guibert F, Graus F, Fleury A et al. Treatment of paraneoplastic neurological syndromes with antineuronal antibodies (Anti-Hu, anti-Yo) with a combination of immunoglobulins, cyclophosphamide, and methylprednisolone. J Neurol Neurosurg Psychiatry 2000; 68: 479-482

120 Rosenfeld MR, Dalmau J. Current therapies for paraneoplastic neurologic syndromes. Curr Treat Options Neurol 2003; 5: 69-77

121 Vernino S, O'Neill BP, Marks RS et al. Immunomodulatory treatment trial for paraneoplastic neurological disorders. Neuro Oncol 2004; 5 : $55-62$

122 Higgins SP, Freemark M, Prose NS. Akanthosis nigricans: a practical approach to evaluation and management. Dermatol Online J 2008; $14: 2$

123 Horiuchi Y, Katsuoka K, Yoshimura $\mathrm{H}$ et al. Acanthosis nigricans and Leser-Trelat sign associated with squamous cell carcinoma and adenocarcinoma of the lung. Int J Dermatol 1986; 25: 459-460

124 Menzies DG, Choo-Kang J, Bruxton PK, Campbell IW. Acanthosis nigricans associated with alveolar cell carcinoma. Thorax 1988; 43: 414415

125 Onai T, Mori M, Akuzawa $M$ et al. A case of lung carcinoma associated with acanthosis nigricans and increased titer of anti-nuclear antibody. Nippon Naika Gakkai Zhasshi 1989; 78: 1607-1608

126 Krwaczyk M, Mykala-Ciesla J, Kolodziej-Jaskula A. Acanthosis nigricans as a paraneoplastic syndrome. Pol Arch Med Wewn 2009; 119: $180-183$

127 Lenzner U, Ramsauer J, Petzoldt W et al. Acanthosis nigricans maligna. Hautarzt 1998; 49: 41-47

128 Schwindt WD, Bernhardt LC, Johnson SAM. Tylosis and intrathoracic neoplasms. Chest 1970; 57: 590-591

129 Nomori $H$, Horio $H$, Iga $R$ et al. Squamous cell carcinoma of the lung associated with palmo-plantar hyperkeratosis. Niho Kyobu Shikkan Gakkai Zasshi 1996; 34: 76 - 79

130 Engin H, Akdogan A, Altundaq O et al. Non-small-cell lung cancer with nonfamilial diffuse palmoplantar keratoderma. J Exp Clin Cancer Res 2002; $21: 45-47$

131 Burgdorf WHC, Goltz RW. Figurate erythemas. In: Fitzpatrick TB, Eisen AZ, Wolff $K$ et al., eds. Dermatology in Internal Medicine. New York: McGraw-Hill 1987: 1010-1018

132 Bazex A, Griffiths A. Acrokeratosis Paraneoplastica: a new cutaneous marker of malignancy. Br J Dermatol 1980; 103: 301 - 306

133 Pecora AL, Landsman L, Imgrund SP et al. Acrokeratosis Paraneoplastica (Bazex' Syndrome): Report of a case and Review of the Literature. Arch Dematol 1983; 119: 820-826

134 Sharma V, Sharma NL, Ranjan N. Acrokeratitis paraneoplastica (Bazex syndrome): Case report and review of the literature. Dermatol Online J 2006; $12: 11$

135 Lelbach A, Muzes G, Feher J. Current perspectives of catabolic mediators of cancer cachexia. Med Sci Monit 2006; 13: 168 - 173

136 Dworzak F, Ferrari P, Gavazzi C et al. Effects of cachexia due to cancer on whole body and skeletal muscle protein turnover. Cancer 1998; 82: $42-48$

137 Giordano A, Calvani M, Petillo $O$ et al. Skeletal muscle metabolism in physiology and in cancer disease. J Cell Biochem 2003; 90: 170-186

138 Harvie MN, Campbell IT, Thatcher N, Baildam A. Changes in body composition in men and women with advanced nonsmall cell lung cancer (NSCLC) undergoing chemotherapy. J Hum Nutr Diet 2003; 16: 323 326

139 Argiles JM, Moore-Carrasco R, Fuster G et al. Cancer cachexia: the molecular mechanism. Int J Biochem Cell Biol 2003; 35: 405-409

140 Argiles JM, Moore-Carrasco R, Busquets S, Lopez-Soriano FJ. Catabolic mediators as targets for cancer cachexia. Drug Discov Today 2008; 8: $838-844$
141 Lelbach A, Munez G, Feher J. Molecular mechanisms of cancer cachexia. Orv Hetil 2004; 46: 2329-2334

142 Brink M, Anwar D, Delafontaine P. Neurohormonal factors in the development of catabolic/anabolic imbalance and cachexia. Int J Cardiol 2002; 85: $111-121$

143 Laviano A, Russo M, Freda Fet al. Neurochemical mechanisms for cancer anorexia. Nutrition 2002; 18: 100 - 105

144 Schaur RJ, Fellier H, Gleispach $H$ et al. Tumor host relations I. Increased plasma cortisol in tumor-bearing humans compared with patients with benign surgical diseases. J Cancer Res Clin Oncol 1979; 93: $281-285$

145 Knapp ML, al-Sheibani S, Riches PG et al. Hormonal factors associated with weight loss in patients with advanced breast cancer. Ann Clin Biochem 1991; 28: 480-486

146 Cariuk P, Lorite MJ, Todorov PT et al. Induction of cachexia in mice by a product isolated from the urine of cachectic cancer patients. Br J Cancer 1997; 76: 606-613

147 Hiraki K, Ishiko O, Tisdale M. Mechanisms of depletion of liver glycogen in cancer cachexia. Biochem Biosphys Res Commun 1997; 241: $49-52$

148 Cella D, Davis K, Breitbart W, Curt G, Fatigue Coalition. Cancer-related fatigue: Prevalence of proposed diagnostic criteria in a United States sample of cancer survivors. J Clin Oncol 2001; 19: 3385-3391

149 Ahlberg K, Ekman T, Gaston-Johansson F, Mock V. Assessment and management of cancer-related fatigue in adults. Lancet 2003; 362: $640-6509$

150 Chaudhuri A, Behan PO. Fatigue in neurological disorders. Lancet 2004; 363: $978-988$

151 Ronnback L, Hansson E. On the potential of glutamate transport in mental fatigue. J Neuroinflammation 2004; 1: 22

152 Ryan JL, Carroll JK, Ryan EP et al. Mechanisms of cancer-related fatigue. Oncologist 2007; 12 (Suppl. 1): $22-34$

153 Castell LM, Yamamoto T, Phoenix J, Newsholme EA. The role of tryptophan in fatigue and different conditions of stress. Adv Exp Med Biol 1999; 467: $697-704$

154 Badawy AA, Morgan CJ, Llewelyn MB et al. Heterogeneity of serum tryptophan concentration and availability to the brain in patients with the chronic fatigue syndrome. J Psychopharmacol 2005; 19 : $385-391$

155 Andrews PLR, Morrow GR, Hickok JT. Mechanisms and models of fatigue associated with cancer and its treatment: Evidence of pre-clinical and clinical studies. In: Armes J, Krishnasamy M, Higginson I eds. Fatigue in Cancer. Oxford: Oxford University Press 1988: 51 - 87

156 Cleare AJ. The neuroendocrinology of chronic fatigue syndrome. Endocr Rev 2003; 24: 236-252

157 Focan C, Focan-Henrard D, Collette J et al. Cancer-associated alteration of circadian rhythms in carcinoembryonic antigen (CEA) and alphafeto-protein (AFP) in humans. Anticancer Res 1986; 6: 1137-1144

158 Mormont MC, Levi F. Circadian-system alterations during cancer processes: A review. Int J Cancer 1997; 70: 241 -247

159 Vgontzas AN, Chrousos GP. Sleep, the hypothalamic-pituitary-adrenal axis, and cytokines: Multiple interactions and disturbances in sleep disorders. Endocrinol Metab Clin North Am 2002; 31: 15-36

160 Sephton S, Spiegel D. Circadian disruption in cancer: A neuroendocrine-immune pathway from stress to disease? Brain Behav Immun 2003; 17: $321-328$

161 Levin RD, Daehler MA, Grutsch JF et al. Circadian function in patients with advanced non-small-cell lung cancer. Br J Cancer 2005; 93: $1202-1208$

162 McCully KK, Natelson BH, Iotti S et al. Reduced oxidative muscle metabolism in chronic fatigue syndrome. Muscle Nerve 1996; 19: 554 560

163 Lane RJ, Barrett MC, Taylor DJ et al. Heterogeneity in chronic fatigue syndrome: Evidence from magnetic resonance spectroscopy of muscle. Neuromuscul Disord 1998; 8: 204-209

164 Forsyth LM, Preuss HG, MacDowell AL et al. Therapeutic effects of ora NADH on the symptoms of patients with chronic fatigue syndrome. Ann Allergy Asthma Immunol 1999; 82: 185-191

165 Konsman JP, Parnet P, Dantzer R. Cytokine-induced sickness behaviour: Mechanisms and implications. Trends Neurosci 2002; 25: $154-159$ 